\title{
The molecular biology and immune control of chronic Toxoplasma gondii infection
}

\author{
Xiao-Yu Zhao and Sarah E. Ewald \\ Department of Microbiology, Immunology and Cancer Biology and the Carter Immunology Center, University of Virginia School of Medicine, Charlottesville, Virginia, USA.
}

\begin{abstract}
Toxoplasma gondii is an incredibly successful parasite owing in part to its ability to persist within cells for the life of the host. Remarkably, at least 350 host species of $T$. gondii have been described to date, and it is estimated that $30 \%$ of the global human population is chronically infected. The importance of $T$. gondii in human health was made clear with the first reports of congenital toxoplasmosis in the 1940 s. However, the AIDS crisis in the 1980 s revealed the prevalence of chronic infection, as patients presented with reactivated chronic toxoplasmosis, underscoring the importance of an intact immune system for parasite control. In the last $\mathbf{4 0}$ years, there has been tremendous progress toward understanding the biology of $T$. gondii infection using rodent models, human cell experimental systems, and clinical data. However, there are still major holes in our understanding of T. gondii biology, including the genes controlling parasite development, the mechanisms of cell-intrinsic immunity to $T$. gondii in the brain and muscle, and the long-term effects of infection on host homeostasis. The need to better understand the biology of chronic infection is underscored by the recent rise in ocular disease associated with emerging haplotypes of $T$. gondii and our lack of effective treatments to sterilize chronic infection. This Review discusses the cell types and molecular mediators, both host and parasite, that facilitate persistent $T$. gondii infection. We highlight the consequences of chronic infection for tissue-specific pathology and identify open questions in this area of host-Toxoplasma interactions.
\end{abstract}

\section{Introduction}

Toxoplasma gondii is a single-cell obligate intracellular protozoan parasite acquired by the eating of contaminated foods. Feline species are T. gondii's definitive hosts, meaning that cats facilitate sexual recombination of the parasite and shed millions of highly infectious, environmentally stable oocysts (1). T. gondii is unique in its incredibly broad intermediate host range, which includes humans, livestock (sheep and pigs are particularly important for human transmission), birds, and rodents, among others (2). These intermediate hosts support the asexual tachyzoite and bradyzoite tissue cyst forms of the parasite. Mollusks, which concentrate oocysts by filtering contaminated water, are an additional vector for transmission to humans (3). After consumption of bradyzoite tissue cysts or oocysts, T. gondii invades the small intestine of its host $(4,5)$. Recent work from Laura Knoll's laboratory suggests that the parasite may sense linoleic acid in the feline gut as a critical signal for sexual stage differentiation in these species (6). Passing through the cat confers a tremendous benefit to the parasite in terms of genetic diversity and range expansion, and facilitating transmission to cats appears to be a major pressure driving parasite evolution. Given the importance of the predator-prey cycle between rodents and cats, rodents may be a particularly important host for T. gondii. As will be discussed, this conclusion is supported by the observations that $T$. gondii expresses a sophisticated cadre of effectors that intersect mouse immune signaling (7-9) and that

Conflict of interest: The authors have declared that no conflict of interest exists. Copyright: $\odot 2020$, American Society for Clinical Investigation.

Reference information: J Clin Invest. 2020;130(7):3370-3380.

https://doi.org/10.1172/JCl136226. infected rodents lose their natural aversion to feline urine $(10,11)$ and can become severely wasted (12-14), all of which may facilitate transmission via predation of a rodent host.

Rates of human T. gondii infection range from $10 \%$ in the United States to over 50\% in France, Colombia, and Brazil (15-17). Acute infection can cause flu-like symptoms; however, immune-competent individuals clear the majority of parasites during acute infection. Surviving parasites persist as slow-growing bradyzoite tissue cysts, most abundant in tissues with limited immune surveillance, including brain, eye, cardiac, and skeletal muscle (18). Contracting T. gondii during pregnancy can be lethal to the fetus, which also has a minimal immune system (19). Tissues that were not classically considered "immune privileged" also harbor parasites, based on the observation that transplant recipients of kidney, liver, heart, or lung have contracted toxoplasmosis from an infected donor (20-24). However, chronic infection in these tissues is almost unstudied, as parasite frequency is incredibly low. The immune response to T. gondii is sustained throughout chronic infection, and this is evident in elevated T. gondii-specific IgG and IFN- $\gamma$ in the sera, both of which are essential for parasite restriction (25). If the immune system is suppressed during chemotherapy, organ transplant, or AIDS, for example, T. gondii can revert to tachyzoite replication $(26,27)$. This process, known as recrudescence, can be lethal if parasitemia is not controlled with drugs. The most frequently prescribed regimens are pyrimethamine combined with sulfadiazine or clindamycin; trimethoprim in combination with sulfamethoxazole can be used as an alternative (28). However, these antiparasitic treatments are poorly tolerated, and hypersensitivity to sulfa drugs is particularly common. Currently, 
no treatments have been developed that clear tissue cysts, maybe because of the slow growth of bradyzoites, their sequestration within neurons, and/or the difficulty of developing drugs that cross the blood-brain barrier. This is an area of outstanding need, as new haplotypes of T. gondii are emerging that associate with severe ocular disease in immune-competent patients $(29,30)$.

\section{Population genetics of T. gondii}

In North America and Europe, environmental isolates of T. gondii predominantly belong to three major strains or types: type I, type II, and type III. These types are notable in that virulence, measured by lethal dose (LD), differs by several logs in inbred strains of mice (e.g., C57BL/6, CBA/J, BALB/c). Type I is the most virulent $\left(\mathrm{LD}_{100}\right.$ of 1-10 tachyzoites), compared with type II ( $\mathrm{LD}_{50}$ of $\left.100-1000\right)$ and type III ( $\mathrm{LD}_{50}$ of $\sim 100,000$ to 1 million), which are substantially less aggressive in vivo $(31,32)$. Human infection is dominated by type II in North America and Europe; however, a fourth type, haplogroup 12, was recently isolated from North American patients and wild animals (33). In Asia and Africa, region-specific clonal lineages have also been isolated (34). Strains that do not fit the pattern of clonal lineage expansion have been identified in South America belonging to haplogroups 4 through 15 (35-37). Whole genome sequencing indicates that genomic admixture and recombination between a limited number of ancestral strains account for T. gondii's genetic diversity. The relationship between strains was determined by comparison of the inheritance pattern of large gene haploblocks. These haploblocks encode virulence-associated, secreted parasite effector proteins, suggesting that the unique assortment of effector alleles may also control pathogenesis and/ or transmission rates (38). Importantly, there is evidence of coevolution between virulent haplotypes and mouse IFN-inducible immunity-related GTPase (IRG) genes, which are critical mediators of cell-intrinsic parasite killing in mouse models $(39,40)$.

\section{Immune determinants of dissemination}

Activating a robust immune response is critical to both host and parasite survival. Bradyzoite cysts are resistant to peptic proteases, but tachyzoites are not: if the host dies before chronic infection is established, parasite transmission does not occur. In keeping with this paradigm, the parasite has evolved effectors that selectively activate host immune cell signaling in addition to strategies to avoid sterilizing immunity. In acute and chronic infection, T. gondii grows and persists within a parasitophorous vacuole membrane (PVM). The PVM is generated from the host plasma membrane as the parasite ratchets its way into the cell using injected parasite effector proteins. This process avoids the lytic environment of the endo/lysosomal compartments and accounts for the parasite's remarkable capacity to infect almost any nucleated cell type in vitro (41). In vivo, however, the cell types harboring the parasite are more limited. After a parasite cyst is ingested, T. gondii invades the distal jejunum of the small intestine in mice $(42,43)$. The precise host cell types mediating invasion (e.g., M cells, epithelial cells) are not clear; however, T. gondii sporozoites and tachyzoites have been observed in intestinal epithelial cells (44). Tachyzoites are also observed within infiltrating immune cells (43-45). The CCL2/CCR2 chemokine axis is a conserved mechanism of monocyte recruitment in mice and humans (46). The parasite effectors
Tg14-3-3 and TgWIP have been shown to promote hypermotility in infected human and murine dendritic cells $(47,48)$. Dendritic cell hypermotility has been observed in vivo, suggesting that it may be a stealth mechanism that facilitates parasite dissemination while avoiding detection by circulating immune effectors $(49,50)$.

\section{Cell-autonomous immunity to $T$. gondii}

The long evolutionary relationship between $T$. gondii and mammalian hosts is evident in analysis of the pathways infected cells use to detect and destroy the parasite (39). Three main arms of innate immune sensing have been described in T. gondii infection: the Tolllike receptors (TLRs), the IFN-inducible GTPases, and the inflammasomes. TLR and IL-1 receptor (IL-1R) signaling through MyD88 is a central mediator of IL-12 secretion and the protective Th1 response to T. gondii (51). In mice that are intraperitoneally infected with T. gondii, the parasite protein profilin directly binds and activates TLR11, contributing to IL-12 production and parasite restriction (52). However, profilin is an actin-modifying protein sequestered within parasites and TLR11 signals from endosomal compartments, suggesting that this pathway may be mostly activated by phagocytosed, dead, or dysfunctional parasites (Figure 1). Consistent with this model, after oral infection, TLR11-deficient mice had minimal defects in their Th1 response compared with mice deficient in MyD88 or TLR2, TLR4, and TLR9; however, treating TLR11deficient mice with antibiotics phenocopied MyD88-deficient mice $(53,54)$. These data indicate that gut commensal microbiota can prime a protective immune response to $T$. gondii independent of parasite recognition by TLR11. It is notable that human TLR11 is a pseudogene, indicating alternative innate sensing mechanisms to detect and destroy T. gondii in human cells.

The inflammasome links detection of microbial components or cell damage associated with infection to the release of IL-1 family cytokines and, often, inflammatory cell death. While the inflammasome response to protozoa is understudied in comparison with bacterial and viral pathogens, what is known about $T$. gondii recognition suggests major differences $(55,56)$. The inflammasome sensors NLRP1 (in mice) and NLRP3 (in mice and humans) have been shown to process and release IL-1 $\beta$ in response to T. gondii infection (Figure 1 and refs. 57-59). Mice deficient in NLRP3, caspase-1, and/or caspase-11 have a higher parasite burden in vivo (57, 58, 60). However, unlike better-studied inflammasome triggers (e.g., the NLRP1 protease anthrax lethal toxin or bacterial pathogens that activate NLRP3), pyroptotic host cell death is not observed in the mouse or human cells (57-59). Unlike murine macrophages, the NLRP3 inflammasome in human monocytes is activated independent of the TLR pathway via Syk and CARD9 signaling; and IL-1 $\beta$ release is independent of the pore-forming gasdermin D (59, 61-63). Open questions in the molecular mechanism of the inflammasome response to $T$. gondii include what parasite signals activate the inflammasome, why proptosis is not engaged, and whether this is the result of active parasite manipulation.

Recent data also suggest crosstalk between the inflammasome and the IFN-inducible GTPases, a pathway that surveys the cell for foreign or damaged membranes and targets them for clearance downstream of IFN- $\gamma$. In human cells the dynamin-superfamily guanylate-binding protein 1 (GBP1) localizes to the PVM; this triggers release of parasite DNA into the host cell cytosol, where it is detected 


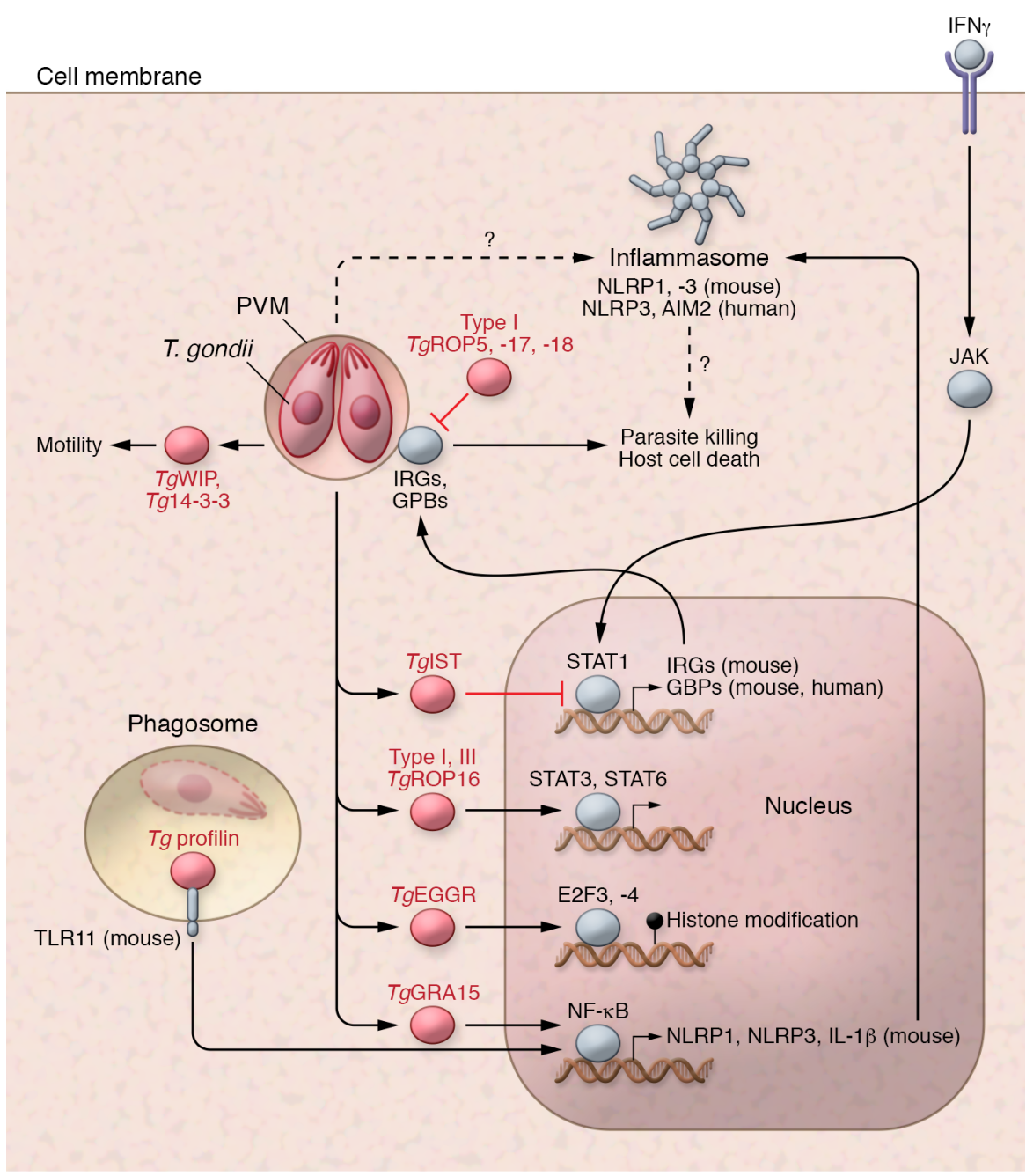

Figure 1. Innate immune signaling and the influence of parasite effectors. T. gondii grows within a parasitophorous vacuole membrane (PVM) that protects the parasite from cytosolic immune sensors and avoids fusion with the endolysosomal compartments containing Toll-like receptors (TLRs). In the mouse, TLR11 recognizes Tg profilin, an actin-modifying protein that is exposed once dead or damaged parasites are phagocytosed. TLR11 is a pseudogene in humans. TgGRA15 can promote host NF- $\kappa B$ phosphorylation and nuclear translocation. In mice, NF- $\kappa B$ stimulation is necessary for transcriptional regulation of the inflammasome components NLRP1, NLRP3, and IL-1; however, human monocytes can engage an NLRP3 inflammasome independent of NF- $\mathrm{KB}$ prestimulation. A detailed mechanism of inflammasome activation, parasite killing, and host cell death remains elusive, particularly in regard to signal integration with IFN- $\gamma$. IFN- $\gamma$ signaling induces STAT1 translocation to the nucleus and upregulation of IFN-responsive genes, including immunity-related GTPases (IRGs, mouse) and guanylate-binding proteins (GBPs, human and mouse), which functions to attack parasite vacuole, leading to parasite killing and host cell death. In human cells, GBP1 is necessary for this process, which leads to AIM2 activation of an alternative apoptosis pathway. The type I parasite rhoptry proteins, TgROP5, 17, and 18, can dismantle the function of the mouse IRGs IRGa6 and IRGb6 at the PVM, inactivating CBP attack and parasite killing. The parasite dense granule effector TgIST is a nuclear repressor of STAT1 transcription. TgROP16 is a kinase that phosphorylates and activates host STAT3 and STAT6. TgEGGR affects host gene expression through E2F3- and E2F4-mediated epigenetic modifications. In infected monocytes and dendritic cells (DCs), TgWIP and 14-3-3 proteins promote cell mobility, a putative mechanism of intracellular parasite dissemination in vivo. action between IRGa6, IRGb6, and phospholipids at the PVM (65). A broader range of mouse GBPs have been implicated in $T$. gondii clearance; however, the mechanism of parasite killing and host cell death in mouse cells is not known (66-68). The importance of the IRG system in parasite clearance is underscored by the observation that type I parasites express a triad of secreted effectors, rhoptry protein 5 (ROP5), ROP17, and ROP18, which bind to and inactivate the GTPase function of IRGa6 and IRGb6 (69, 70). This inactivation is a major mechanism of type-specific virulence, as type II and type III parasites express alleles of Rop 5 or Rop18, respectively, that cannot effectively subvert IRG attack. Although there has been tremendous progress toward identifying the classes of cell-autonomous immune signaling in response to T. gondii, the field lacks an integrated model of cell-autonomous sensing across these pathways for both mouse and human systems, particularly in cell types other than fibroblast, monocyte, and macrophage.

\section{Innate instruction of adaptive immunity}

T. gondii recognition by innate immune sensors triggers a Th1-polarized, $\mathrm{CD} 8^{+} \mathrm{T}$ cell-dependent immune response that is necessary for host survival. There are many excellent reviews on the immunobiology of infection $(7,8,71,72)$, so we will touch briefly on aspects of the acute immune response that are necessary for the progression to chronic infection. Mice deficient in IL-12, TNF- $\alpha$, and IFN- $\gamma$ or their signaling pathways die of parasite overgrowth in acute infection (73-76). IFN- $\gamma$ and IL-12 deficiency is rare in humans and has not been correlated with increased susceptibility to toxoplasmosis; however, monocyte-derived macrophages from IFNGR1-deficient patients fail to restrict $T$. gondii after IFN- $\gamma$ stimulation compared with healthy-donor macrophages $(77,78)$. Mice deficient in the IL-6 pathway fail to mount a protective B cell response and die in early chronic infection (79). IL-10 and regulatory T cells play an equally important role in host survival by the inflammasome sensor AIM2 (Figure 1 and refs. 63, 64). For reasons that are still unclear, a pyroptotic inflammasome response is not engaged; instead, an alternative apoptotic pathway of host cell death is activated $(63,64)$. Unlike the human system, mice rely on an expanded family of p47 IRGs to detect the parasite vacuole downstream of IFN- $\gamma$. Mouse IRGM1 and IRGM3 regulate the inter- by limiting the magnitude of the inflammatory response and bystander damage (80-85).

A growing number of T. gondii effectors have been identified that are secreted into the host cell to control immune signaling. These effectors are released from secretory organelles known as the rhoptries (ROP) and the dense granules (GRA), and many of 

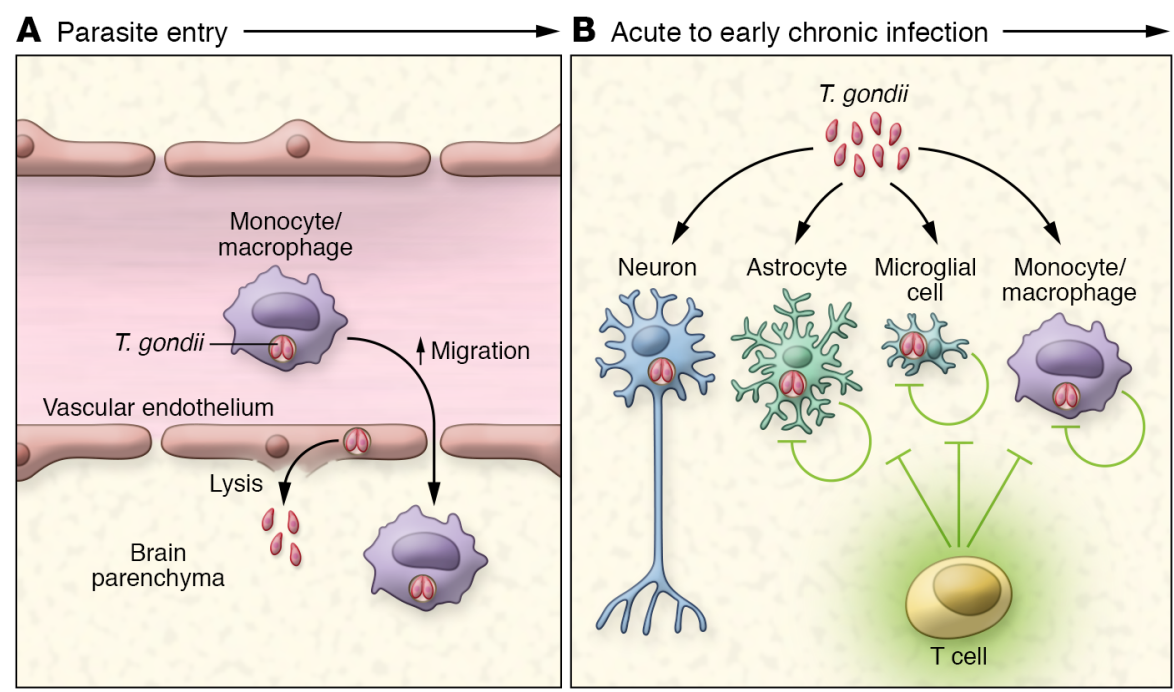

\section{Chronic infection}

Brain immune response

Cell-intrinsic clearance

IFN- - , TNF- $\alpha$, perforin

Figure 2. T. gondii entry and control of persistent infection in the brain. (A) In acute infection, T. gondii is frequently observed in immune cells, including monocytes and dendritic cells, with hypermigratory behavior. During infection, blood-brain barrier (BBB) permeability increases and monocytes accumulate in the endothelial lumen, interacting with endothelial cells. These observations have led to the hypothesis that migratory immune cells deliver T. gondii to the BBB and, perhaps, smuggle them into the brain. Replicating parasites are also observed in brain endothelial cells, whose subsequent lysis may be a mechanism of $T$. gondii entry into the brain. (B) During acute infection parasites are observed infecting neurons, astrocytes, microglia, and infiltrating immune cells. Astrocytes and microglia as well as peripheral monocytes can clear parasites with cell-autonomous immune pathways. (C) As chronic infection progresses, infected astrocytes and microglia or the parasites within them are cleared and cysts are primarily observed within neurons. Most parasite cysts are not associated with immune infiltrate; however, individual parasites or parasite debris can be observed colocalizing with immune infiltrate.

the effectors are polymorphic across strains and play a role in virulence (Figure 1). GRA15 activates NF- $\kappa$ B, and GRA24 activates the 38 MAPK pathway to promote expression of IL-12 and IL-18, the upstream regulators of IFN- $\gamma$ and $\mathrm{T}$ cell activation $(86,87)$. ROP16 is a serine-threonine kinase that directly phosphorylates STAT3 and STAT6 and dampens IL-12 production, which may be consistent with the concept that fine-tuning immune response is necessary for host survival and parasite transmission $(88,89)$. However, the effector $\mathrm{TgIST}$ was recently identified as an inhibitor of IFN receptor signaling. TgIST binds STAT1 and forms an inhibitory complex with the nucleosome remodeling deacetylase (Mi-2/ NuRD) complex. This suppresses transcription of IRF1-dependent cytokines, MHC class II expression and antigen presentation, and inducible nitric oxide synthase (iNOS) expression, which kills parasites by producing reactive nitrogen species $(90,91)$. Similarly, TgTEEGR interacts with E2F3 and E2F4 transcription factors, and forms a nuclear complex with a catalytic subunit of polycomb repressor complex to block NF- $\mathrm{KB}-$ mediated expression of proinflammatory cytokines like IL-1 $\beta$ and IL-6 (92). These effectors are among 200-300 predicted secreted effector proteins in the parasite genome, the majority of which have not been characterized, particularly in the context of chronic infection.

\section{Parasite entry to the brain}

In chronic infection, the central nervous system contains the highest frequency of parasites per gram of tissue. The potential implications of neural infection for host behavior and homeostasis have led to great interest in understanding the biology of $T$. gondii infec- tion in the brain. Our understanding of chronic central nervous system infection is almost exclusively based on murine models of infection. There are many open questions, beginning with how the parasite traverses the blood-brain barrier (BBB). Using intravital microscopy, T. gondii has been imaged replicating within brain endothelial cells and then directly entering the brain (93). Mice infected intravenously with the T. gondii RH strain had a higher brain parasite load than mice infected with the CPS strain, which cannot replicate in vivo, suggesting that $T$. gondii growth within vascular endothelial cells may be an important stopover before direct entry into the brain (Figure 2A and ref. 93). Perfusion of Evans blue dye shows increased BBB permeability during chronic T. gondii infection, accompanied by reduced blood flow and capillary rarefication which may permit immune cell entry into the brain (94). Using intravital microscopy, CCR2 ${ }^{+}$monocytes are found to accumulate, exhibiting rolling and cradling behavior at the BBB (95). This observation, coupled with the high frequency of infection of dendritic cells and their hypermotility phenotype, has led to the Trojan horse hypothesis: that parasites traverse the $\mathrm{BBB}$ within immune cells (Figure $2 \mathrm{~A}$ and refs. 49, 96). Although direct evidence for this model is lacking, antibody depletion of CD11 $\mathrm{b}^{+}$ leukocytes correlated with reduced brain parasite load; and adoptive transfer of $T$. gondii-infected CD $11 \mathrm{c}^{+}$or $\mathrm{CD} 11 \mathrm{~b}^{+}$cells into naive mice led to neural infection (97).

\section{Chronic infection in the central nervous system}

Analysis of mouse brain sections and an extremely limited number of healthy human brain samples indicates that most intracellular 


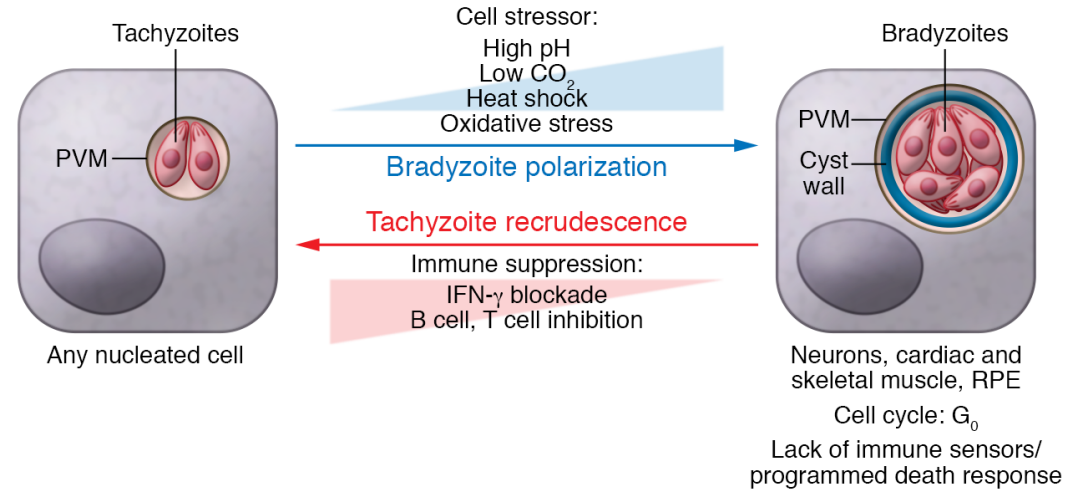

Figure 3. Environmental and host cell-specific pressures driving the $T$. gondii tachyzoite to bradyzoite transition. Left: $T$. gondii tachyzoites can invade almost any nucleated host cell type and grow within the PVM formed from host plasma membrane. In vitro, a range of tissue culture stress conditions can upregulate bradyzoite-specific genes. As parasites polarize to a bradyzoite transcriptional profile, they synthesize a heavily glycosylated cyst wall beneath the PVM. The frequency and rate of bradyzoite differentiation are also influenced by the host cell type, cell cycle status, the host cell lifespan, and inflammatory signals in vitro. In vivo, cysts are most frequently observed in neurons, cardiac muscle, skeletal muscle, and retinal pigment epithelial cells. If the host is immune-suppressed, parasites shift toward a replicative tachyzoite form in a process referred to as recrudescence, which is associated with tissue damage, particularly in the eye.

cysts are not associated with immune infiltration (98). However, within the same brain section, inflammatory foci can be observed containing parasites or parasite debris, activated microglia, macrophages, and T cells (99). Depleting IFN- $\gamma$ or $\mathrm{CD}^{+}$and $\mathrm{CD}^{+} \mathrm{T}$ cells leads to parasite recrudescence (100). Taken together these data suggest that intracellular cysts are relatively immunologically silent; however, cysts that lyse (spontaneously or through recrudescence) are recognized and quickly contained by infiltrating immune cells (Figure 2C).

Experiments using parasites engineered to secrete Cre recombinase in Cre reporter mice have demonstrated that neurons are the major cell type interacting with the parasite in the brain, although $\mathrm{T}$ cells, monocytes or macrophages, microglia, and astrocytes are reporter-positive early in brain infection (Figure 2B and refs. 101-103). These data also suggest that rather than having a tropism for neurons, $T$. gondii is cleared from non-neuronal cell types in the brain. Consistent with this model, disabling the IFN- $\gamma$ signaling in mouse astrocytes by knocking out the transcription factor STAT1 led to greater incidence of cysts within astrocytes (104); and IFN- $\gamma$ depletion increased the percentage of infected astrocytes (102). Subsequently, the ability of mouse astrocytes to restrict T. gondii growth in response to IFN- $\gamma$ was shown to depend on IRGM3 (IGTP), not iNOS; IRGM3 and IRGa6 disrupted the PVM and, in one study, led to parasite egress (105-107). In human astrocytes, IL-1 $\beta$ in combination with IFN- $\gamma$ induced iNOSdependent killing of T. gondii (108), whereas TNF- and IFN- $\gamma$ limited T. gondii growth by tryptophan starvation via upregulated indoleamine 2,3-dioxygenase (IDO) (109). The parasite effector TgGRA15 has been shown to limit IDO-mediated parasite restriction in cultured glioblastoma and neuroblastoma cell lines (110). IFN- $\gamma$ in combination with TNF- $\alpha$ or LPS has also been shown to activate parasite killing functions of human and murine microglia through iNOS-dependent and -independent mechanisms (111-113). Microglia can also produce IFN- $\gamma$ and TNF- $\alpha$, which are critical for central nervous system restriction of the infection (114); IFN- $\gamma$, in particular, has been shown to induce adhesion molecule expression on vascular endothelial cells and promote the expression of CXCL9, CXCL10, and CCL5, which recruit peripheral immune cells to the brain $(115,116)$. Most of these data are from in vitro experiments, and better tools to study microglia and astrocyte function in vivo will be important to clarify which pathways control central nervous system infection.

While brain-resident immune cells contribute to $T$. gondii restriction, the role of cellautonomous immunity in neurons is less clear. A recent study using OVA-expressing parasites and conditional MHC class I-deficient mice demonstrated that neurons can present T. gondiiderived antigens to initiate a $\mathrm{CD}^{+} \mathrm{T}$ cell response (117); however, whether endogenous parasite epitopes are efficiently presented on neurons is yet to be examined. Brain-infiltrating $\mathrm{CD}^{+} \mathrm{T}$ cells have been shown to control cyst burden indirectly through IFN- $\gamma$ secretion, and, to a lesser extent, via perforin-dependent killing of infected cells (118-120). It is notable that perforin has been shown to trigger parasite egress in vitro, suggesting that perforin may limit parasite growth but other cells are responsible for parasite killing, potentially through cell-autonomous immunity (121). A minimal reliance on perforin-mediated $T$. gondii clearance also fits a model wherein cellular cytotoxicity should be limited in the brain to promote survival of neurons, which have an extremely limited regenerative capacity.

\section{Parasite determinants of cyst formation and chronic infection}

Currently there are no therapeutic tools that effectively target bradyzoite cysts and sterilize chronic infection. Our understanding of bradyzoite biology is weaker than our understanding of tachyzoite biology. This is linked to long-standing technical challenges associated with genetic manipulation of bradyzoite-specific genes that are required to perform "necessary and sufficient" experiments. However, the recent bloom in CRISPR/Cas9 tools has led to gains in this arena $(122,123)$.

The transition between tachyzoite and bradyzoite has commonly been referred to as "switching"; however, recent studies suggest that stage conversion is a continuum under epigenetic and transcriptional regulation rather than a finite life stage. Bradyzoite polarization can be induced by cell stressors including alkaline media, heat shock, and oxidative stress (refs. 124-126 and Figure 3). IFN- $\gamma$ treatment has been shown to induce bradyzoite gene expression in infected macrophages but not fibroblasts, suggesting that cell type-specific differentiation signals may also exist (127). Compared with fibroblasts, infected neuronal or skeletal muscle cells support a stronger expression of bradyzoite markers and a higher frequency of cyst development (128). It is worth 
noting that neurons and muscle cell types are historically difficult to culture, suggesting that cell stress signals may be relevant to bradyzoite development in these models. However, terminally differentiated myotubes are reported to support a higher frequency of bradyzoites compared with dividing myoblast progenitor cells, suggesting that cell cycle may provide developmental cues for the parasite development as well (129).

Although the precise signals are unclear, histone methylation and acetylation are important epigenetic regulators of bradyzoite differentiation. Treating tachyzoites with arginine methyltransferase inhibitor, AMI-I, induces a reduction of histone H3R17 methylation and bradyzoite differentiation in vitro (130). The $T$. gondii histone acetyltransferase $T g G C N 5 a$ is enriched at promoter regions of bradyzoite-specific genes, and TgGCN5adeficient parasites fail to upregulate the bradyzoite markers Bag1 and $L d h 2$ under stress (131). Treating infected cells with the histone deacetylase inhibitor FR235222 induces bradyzoite differentiation through inhibiting TgHDAC3 (132). Phosphorylation of the T. gondii eukaryotic initiation factor $2 \alpha$ subunit (TgeIF $2 \alpha$ ) is enhanced under stress conditions and is necessary for bradyzoite differentiation (133). Guanabenz, an eIF2 $\alpha$ dephosphorylation inhibitor, has been shown to impair tachyzoite proliferation and promote bradyzoite differentiation in vitro (134).

The ApiAP2 family of transcription factors are emerging as central regulators of bradyzoite differentiation. This family consists of 67 genes, many of which are associated with bradyzoite stage-specific expression. Specifically, AP2XI-4- and AP2IV-3knockout parasites have reduced expression of bradyzoitespecific genes after in vitro switch; and AP2XI-4-null T. gondii forms fewer cysts in mice $(135,136)$. AP2IV-4 knockouts express some bradyzoite-specific genes under tachyzoite culture, but had fewer brain cysts in mice (137). Using a CRISPR/Cas9 guide RNA library targeting mostly AP2 domain-containing proteins and predicted nucleic acid-binding proteins, bradyzoite formation deficient 1 (BFD1), a Myb-like transcription factor, was recently identified as a key regulator of bradyzoite differentiation in vitro and in vivo in mice. Interestingly, $B f d 1 \mathrm{mRNA}$ is expressed in tachyzoites; however, protein expression is only induced by stress conditions (138). It remains to be seen whether immunosuppression induces any parasite recrudescence in mice infected with BFD1-deficient parasites and how BFD1- and AP2-family proteins coordinate bradyzoite differentiation.

T. gondii bradyzoite cysts are often defined by formation of a cyst wall consisting of heavily glycosylated proteins underneath the PVM (139). The cyst wall is essential for transmission, protecting the parasite from gastric proteases and the low $\mathrm{pH}$ of the stomach. Parasites deficient in the cyst wall-localized bradyzoite pseudokinase 1 (BPK1) were more sensitive to pepsin digestion and less orally infectious than WT parasites (140). Parasites that were rendered genetically deficient in cyst glycoproteins, including loss of the nucleotide-sugar transporter $\mathrm{TgNST} 1$ or the heavily glycosylated cyst wall protein $\mathrm{TgCST} 1$, have defects in cyst number, cyst stability, and infectivity during oral infection (141-143). The cyst wall may also protect bradyzoites from enzymatic attack during chronic infection. The Wilson laboratory demonstrated that chitinase-expressing, alternatively activated (M2) macrophages were able to recognize and degrade chitin-like polysaccharides in the cyst wall (144). Consistent with this observation, a GWAS identified single-nucleotide polymorphisms in the intergenic region of the human CHIA locus, which expresses chitinase, that were significantly associated with $T$. gondii infection (145).

\section{Ocular toxoplasmosis}

T. gondii infection is the most frequent cause of posterior uveitis, also referred to as chorioretinitis or inflammation of the retina and choroid (pigmented vascular coat of the eye) (30). This is one area of T. gondii infection that has been more extensively studied in patients than in animal models, which have been limited until recently. Type II strains, most frequently associated with infection in Europe and North America, are associated with chorioretinitis $(146,147)$. Historically, ocular toxoplasmosis was associated with congenital infection; however, rates of disease associated with postnatal infection are rising and associated with new T. gondii strains (148). Over $70 \%$ of patients presenting with acute ocular toxoplasmosis already have ocular scars, suggesting that disease progression is driven by the inflammatory response to recrudescent $T$. gondii leading to the accumulation of tissue damage over time (149). Immune-competent individuals are able to control ocular infection, but early antiparasitic treatment is critical to limit the extent of retinal damage (150). Human retinal vascular endothelial cells are more sensitive to infection than other endothelial cell types, suggesting a potential mechanism of entry into the eye (151). T. gondii cysts have been observed in retinal pigmented epithelial cells (152). In a mouse model of ocular toxoplasmosis, retinal pigment epithelial cells and infiltrating immune cells expressed the T cell inhibitory ligand PD-L1 (153). This may be an important mechanism to limit tissue pathology, although the parasites may exploit this axis for persistence. IFN- $\gamma$ and IL-6, which are both critical in restricting systematic parasitemia $(79,100)$, were elevated in the vitreous humor of mice with ocular lesions. However, intraocular injection of an IFN- $\gamma$-blocking antibody impaired parasite control and worsened tissue damage, while, perhaps counterintuitively, injection of an IL-6-blocking antibody improved parasite control and minimized ocular damage (154-156). Patients infected with virulent South American haplotypes of T. gondii, which have been associated with aggressive chorioretinitis, had less IFN- $\gamma$ and IL-17 but higher IL-13 and IL-6 levels in the eye compared with European patients infected with virulent type I (157). However, it is currently not clear whether these differences in immune regulation control ocular disease severity.

\section{Behavioral and metabolic changes of chronic $T$. gondii infection}

In mice and rats, infection with $T$. gondii leads to a well-established loss of innate aversion behavior to felines, which has been proposed to benefit the parasite by facilitating transmission via predation $(11,158,159)$. Whether these behavioral phenotypes are driven by specific changes in neural activity or a more general effect of inflammation is an open question. The observation that $T$. gondii expresses two aromatic amino acid hydrolases that produce L-DOPA, AAH1, and AAH2 led to the hypothesis that the parasite could modulate dopaminergic neuron function. However, deletion of AAH2 failed to alter brain dopamine levels, neuroinflam- 
mation, or behavioral alterations in T. gondii-infected mice (160, 161), although these genes are necessary for oocyst development in the cat (162). Notably, mice infected with an avirulent mutant of type I T. gondii or the related organism Neospora caninum, which are cleared before establishing chronic infection, exhibit loss of aversion behavior even though chronic infection is not sustained (163). These data suggest that acute inflammation may be sufficient to trigger sustained behavioral changes, although the molecular bases for behavioral changes in T. gondii infection are unclear. Recently, the olfactory GPCR trace amine-associated receptor 4 (TAAR4) was shown to recognize 2-phenylethylamine, a metabolite enriched in urine of predators, including feline species. There is no homolog of TAAR4 in humans, but mice deficient in TAAR4 do not engage in avoidance behavior to bobcat and mountain lion urine (164). That the olfactory neurons expressing TAAR4 are altered or damaged during T. gondii infection is a compelling hypothesis that remains to be tested.

Sustained interaction with the immune system is a hallmark of T. gondii infection: throughout chronic infection humans and mice have high titers of T. gondii-specific IgG and sera cytokines. There is growing evidence that $T$. gondii infection is associated with cachexia in mice, an immune-metabolic disease of sustained muscle wasting. Cachexia positively correlates with parasite load and inflammation severity; however, hypermetabolic weight loss cannot be rescued by diet supplementation $(13,165-167)$. In oral infection, intestinal barrier inflammation resolves during chronic infection, but commensal dysbiosis does not $(14,168)$; however, dysbiosis is not sufficient for cachexia, as uninfected cage mates experienced a similar microbial shift but did not develop cachexia (14). Chronically infected mice have sustained changes in splenic and lymph node architecture and are more susceptible to acute viral challenge (169). Moreover, cachectic mice were more susceptible to LPS challenge than mice that recovered weight (170). Recently, mice deficient in the IL-1R axis were shown to recover from acute cachectic weight loss, although chronic parasite burden was similar to that in wild-type mice (171). A study from the Wohlfert laboratory showed that infection-induced myositis could be reversed by depletion of regulatory $\mathrm{T}$ cells, which were enriched in skeletal muscle (172). Parasite biology that promotes behavior modification and cachexia in rodent hosts may provide a selective advantage to $T$. gondii by increasing the likelihood of predation and transmission to feline hosts. It is important to note that there is currently no evidence of cachexia in immune-competent humans with chronic T. gondii infection. However, cachexia is a predictor of mortality in almost every chronic human disease with limited experimental tools to probe sustained disease. The interaction between T. gondii and mice is proving an informative model to understand the pathophysiology of cachexia, which can be applied to understand other disease settings.

\section{Conclusions and future directions}

T. gondii's ability to establish a persistent chronic infection is essential for parasite transmission. However, there is much to learn about this stage of infection in animal and human hosts. Deep sequencing has unraveled a far greater diversity in T. gondii gene assortment than originally thought, which has opened the door to understanding how parasite genetics influences pathology associated with chronic infection. CRISPR/Cas9 tools are expanding our ability to manipulate the $T$. gondii genome to understand how gene expression in bradyzoites controls differentiation, cyst stability, and oral infectivity of the parasite. Bradyzoite biology is intimately linked to the immune response during chronic infection. The coming decades will likely reveal mechanisms of cell-autonomous immunity to chronic T. gondii infection in the brain and other chronically infected tissues, as well as reveal the costs of the chronic inflammatory response for host homeostasis. A better understanding of this biology is needed to develop therapeutic strategies that effectively target bradyzoite cysts. Given the long evolutionary relationship between mammalian hosts and T. gondii, such studies are likely to discover important information about the regulation of immune functions during chronic inflammation more broadly.

Address correspondence to: Sarah E. Ewald, Carter Immunology Center MR-6 3706, University of Virginia School of Medicine, Charlottesville, Virginia 22908, USA. Phone: 434.924.1925; Email: se2s@virginia.edu.
1. Dubey JP, Miller NL, Frenkel JK. The Toxoplasma gondii oocyst from cat feces. J Exp Med. 1970;132(4):636-662.

2. Black MW, Boothroyd JC. Lytic cycle of Toxoplasma gondii. Microbiol Mol Biol Rev. 2000;64(3):607-623.

3. Jones JL, Dargelas V, Roberts J, Press C, Remington JS, Montoya JG. Risk factors for Toxoplasma gondii infection in the United States. Clin Infect Dis. 2009;49(6):878-884.

4. Dubey JP, Speer CA, Shen SK, Kwok OC, Blixt JA. Oocyst-induced murine toxoplasmosis: life cycle, pathogenicity, and stage conversion in mice fed Toxoplasma gondii oocysts. J Parasitol. 1997;83(5):870-882.

5. Speer CA, Dubey JP. Ultrastructure of early stages of infections in mice fed Toxoplasma gondii oocysts. Parasitology. 1998;116(pt 1):35-42.

6. Martorelli Di Genova B, Wilson SK, Dubey JP,
Knoll LJ. Intestinal delta-6-desaturase activity determines host range for Toxoplasma sexual reproduction. PLoS Biol. 2019;17(8):e3000364.

7. Yarovinsky F. Innate immunity to Toxoplasma gondii infection. Nat Rev Immunol. 2014;14(2):109-121.

8. Sasai M, Pradipta A, Yamamoto M. Host immune responses to Toxoplasma gondii. Int Immunol. 2018;30(3):113-119.

9. Coombes JL, Hunter CA. Immunity to Toxoplasma gondii-into the 21st century. Parasite Immunol. 2015;37(3):105-107.

10. Dewan A, Pacifico R, Zhan R, Rinberg D, Bozza T. Non-redundant coding of aversive odours in the main olfactory pathway. Nature. 2013;497(7450):486-489.

11. Boillat M, et al. Neuroinflammation-associated aspecific manipulation of mouse predator fear by Toxoplasma gondii. Cell Rep. 2020;30(2):320-334.e6.

12. Jin RM, Blair SJ, Warunek J, Heffner RR, Blader IJ, Wohlfert EA. Regulatory T cells promote myositis and muscle damage in Toxoplasma gondii infection. J Immunol. 2017;198(1):352-362.

13. Arsenijevic D, Girardier L, Seydoux J, Chang HR, Dulloo AG. Altered energy balance and cytokine gene expression in a murine model of chronic infection with Toxoplasma gondii. Am J Physiol. 1997;272(5 pt 1):E908-E917.

14. Hatter JA, et al. Toxoplasma gondii infection triggers chronic cachexia and sustained commensal dysbiosis in mice. PLoS One. 2018;13(10):e0204895.

15. Cañón-Franco WA, López-Orozco N, GómezMarín JE, Dubey JP. An overview of seventy years of research (1944-2014) on toxoplasmosis in Colombia, South America. Parasit Vectors. 2014;7:427. 
16. Guigue N, et al. Continuous decline of Toxoplasma gondii seroprevalence in hospital: a 1997-2014 longitudinal study in Paris, France. Front Microbiol. 2018;9:2369.

17. Dubey JP, Lago EG, Gennari SM, Su C, Jones JL. Toxoplasmosis in humans and animals in Brazil: high prevalence, high burden of disease, and epidemiology. Parasitology. 2012;139(11):1375-1424.

18. Dubey JP, Lindsay DS, Speer CA. Structures of Toxoplasma gondii tachyzoites, bradyzoites, and sporozoites and biology and development of tissue cysts. Clin Microbiol Rev.1998;11(2):267-299.

19. Wong SY, Remington JS. Biology of Toxoplasma gondii. AIDS. 1993;7(3):299-316.

20. Assi MA, Rosenblatt JE, Marshall WF. Donor-transmitted toxoplasmosis in liver transplant recipients: a case report and literature review. Transpl Infect Dis. 2007;9(2):132-136.

21. Galván-Ramírez ML, Sánchez-Orozco LV, Gutiérrez-Maldonado AF, Rodriguez Pérez LR. Does Toxoplasma gondii infection impact liver transplantation outcomes? A systematic review. JMed Microbiol. 2018;67(4):499-506.

22. Renoult E, et al. Toxoplasmosis in kidney transplant recipients: report of six cases and review. Clin Infect Dis. 1997;24(4):625-634.

23. Montoya JG, et al. Infectious complications among 620 consecutive heart transplant patients at Stanford University Medical Center. Clin Infect Dis. 2001;33(5):629-640.

24. Wreghitt TG, et al. Toxoplasmosis in heart and heart and lung transplant recipients. JClin Pathol. 1989;42(2):194-199.

25. Sturge CR, Yarovinsky F. Complex immune cell interplay in the gamma interferon response during Toxoplasma gondii infection. Infect Immun. 2014;82(8):3090-3097.

26. Montoya JG, Liesenfeld O. Toxoplasmosis. Lancet. 2004;363(9425):1965-1976.

27. Luft BJ, Remington JS. Toxoplasmic encephalitis in AIDS. Clin Infect Dis. 1992;15(2):211-222.

28. Dunay IR, Gajurel K, Dhakal R, Liesenfeld O, Montoya JG. Treatment of Toxoplasmosis: historical perspective, animal models, and current clinical practice. Clin Microbiol Rev. 2018;31(4):e00057-17.

29. Khan A, et al. Genetic divergence of Toxoplasma gondii strains associated with ocular toxoplasmosis, Brazil. Emerging Infect Dis. 2006;12(6):942-949.

30. Maenz M, Schlüter D, Liesenfeld O, Schares G, Gross U, Pleyer U. Ocular toxoplasmosis past, present and new aspects of an old disease. Prog Retin Eye Res. 2014;39:77-106.

31. Sibley LD, Boothroyd JC. Virulent strains of Toxoplasma gondii comprise a single clonal lineage. Nature. 1992;359(6390):82-85.

32. Su C, Howe DK, Dubey JP, Ajioka JW, Sibley LD. Identification of quantitative trait loci controlling acute virulence in Toxoplasma gondii. Proc Natl Acad Sci U S A. 2002;99(16):10753-10758.

33. Khan A, Dubey JP, Su C, Ajioka JW, Rosenthal BM, Sibley LD. Genetic analyses of atypical Toxoplasma gondii strains reveal a fourth clonal lineage in North America. Int J Parasitol. 2011;41(6):645-655.

34. Galal L, Hamidović A, Dardé ML, Mercier M. Diversity of Toxoplasma gondii strains at the global level and its determinants. Food Waterborne Parasitol. 2019;15:e00052.

35. Su C, et al. Globally diverse Toxoplasma gondii isolates comprise six major clades originating from a small number of distinct ancestral lineages. Proc Natl Acad Sci U S A. 2012;109(15):5844-5849.

36. Minot $S$, et al. Admixture and recombination among Toxoplasma gondii lineages explain global genome diversity. Proc Natl Acad Sci U S A. 2012;109(33):13458-13463.

37. Shwab EK, et al. Geographical patterns of Toxoplasma gondii genetic diversity revealed by multilocus PCR-RFLP genotyping. Parasitology. 2014;141(4):453-461.

38. Lorenzi $\mathrm{H}$, et al. Local admixture of amplified and diversified secreted pathogenesis determinants shapes mosaic Toxoplasma gondii genomes. Nat Commun. 2016;7:10147.

39. Müller UB, Howard JC. The impact of Toxoplasma gondii on the mammalian genome. Curr Opin Microbiol. 2016;32:19-25.

40. Hassan MA, Olijnik AA, Frickel EM, Saeij JP. Clonal and atypical Toxoplasma strain differences in virulence vary with mouse sub-species. Int $J$ Parasitol. 2019;49(1):63-70.

41. Mordue DG, Håkansson S, Niesman I, Sibley LD. Toxoplasma gondii resides in a vacuole that avoids fusion with host cell endocytic and exocytic vesicular trafficking pathways. Exp Parasitol. 1999;92(2):87-99.

42. Molloy MJ, et al. Intraluminal containment of commensal outgrowth in the gut during infection-induced dysbiosis. Cell Host Microbe. 2013;14(3):318-328

43. Gregg B, et al. Replication and distribution of Toxoplasma gondii in the small intestine after oral infection with tissue cysts. Infect Immun. 2013;81(5):1635-1643

44. Coombes JL, et al. Motile invaded neutrophils in the small intestine of Toxoplasma gondiiinfected mice reveal a potential mechanism for parasite spread. Proc Natl Acad Sci U S A. 2013;110(21):E1913-E1922.

45. Courret N, Darche S, Sonigo P, Milon G, Buzoni-Gâtel D, Tardieux I. CD11c- and CD11b-expressing mouse leukocytes transport single Toxoplasma gondii tachyzoites to the brain. Blood. 2006;107(1):309-316.

46. Safronova A, et al. Alarmin S100A11 initiates a chemokine response to the human pathogen Toxoplasma gondii. Nat Immunol. 2019;20(1):64-72.

47. Weidner JM, et al. Migratory activation of parasitized dendritic cells by the protozoan Toxoplasma gondii 14-3-3 protein. Cell Microbiol. 2016;18(11):1537-1550.

48. Sangaré LO, et al. In vivo CRISPR screen identifies TgWIP as a Toxoplasma modulator of dendritic cell migration. Cell Host Microbe. 2019;26(4):478-492.e8.

49. Lambert H, Hitziger N, Dellacasa I, Svensson M, Barragan A. Induction of dendritic cell migration upon Toxoplasma gondii infection potentiates parasite dissemination. Cell Microbiol. 2006;8(10):1611-1623.

50. Ólafsson EB, Ross EC, Varas-Godoy M, Barragan A. TIMP-1 promotes hypermigration of Toxoplasma-infected primary dendritic cells via CD63-ITGB1-FAK signaling. J Cell Sci. 2019;132(3):jcs225193.

51. Scanga CA, et al. Cutting edge: MyD88 is required for resistance to Toxoplasma gondii infection and regulates parasite-induced IL-12 production by dendritic cells. J Immunol. 2002;168(12):5997-6001.

52. Yarovinsky F, et al. TLR11 activation of dendritic cells by a protozoan profilin-like protein. Science 2005;308(5728):1626-1629.

53. Denkers EY. A gut feeling for microbes: getting it going between a parasite and its host. Cell Host Microbe. 2009;6(2):104-106.

54. Benson A, Pifer R, Behrendt CL, Hooper LV, Yarovinsky F. Gut commensal bacteria direct a protective immune response against Toxoplasma gondii. Cell Host Microbe. 2009;6(2):187-196.

55. Broz P, Dixit VM. Inflammasomes: mechanism of assembly, regulation and signalling. Nat Rev Immunol. 2016;16(7):407-420.

56. Swanson KV, Deng M, Ting JP. The NLRP3 inflammasome: molecular activation and regulation to therapeutics. Nat Rev Immunol. 2019;19(8):477-489.

57. Ewald SE, Chavarria-Smith J, Boothroyd JC. NLRP1 is an inflammasome sensor for Toxoplasma gondii. Infect Immun. 2014;82(1):460-468.

58. Gorfu G, et al. Dual role for inflammasome sensors NLRP1 and NLRP3 in murine resistance to Toxoplasma gondii. mBio. 2014;5(1):e01117-13.

59. Gov L, Schneider CA, Lima TS, Pandori W, Lodoen MB. NLRP3 and potassium efflux drive rapid IL-1 $\beta$ release from primary human monocytes during Toxoplasma gondii infection. J Immunol. 2017;199(8):2855-2864.

60. Coutermarsh-Ott SL, Doran JT, Campbell C, Williams TM, Lindsay DS, Allen IC. Caspase-11 modulates inflammation and attenuates Toxoplasma gondii pathogenesis. Mediators Inflamm 2016;2016:9848263.

61. Pandori WJ, Lima TS, Mallya S, Kao TH, Gov L, Lodoen MB. Toxoplasma gondii activates a SykCARD9-NF- $\mathrm{BB}$ signaling axis and gasdermin $D$-independent release of IL-1 $\beta$ during infection of primary human monocytes. PLoS Pathog. 2019;15(8):e1007923

62. Gov L, Karimzadeh A, Ueno N, Lodoen MB. Human innate immunity to Toxoplasma gondii is mediated by host caspase- 1 and ASC and parasite GRA15. mBio. 2013;4(4):e00255-13.

63. Fisch D, et al. Human GBP1 is a microbe-specific gatekeeper of macrophage apoptosis and pyroptosis. EMBO J. 2019;38(13):e100926.

64. Fisch D, et al. Human GBP1 differentially targets Salmonella and Toxoplasma to license recognition of microbial ligands and caspase-mediated death [pulished online Apr 23, 2020. bioRxiv. https://doi.org/10.1101/792804.

65. Lee Y, et al. Initial phospholipid-dependent Irgb6 targeting to Toxoplasma gondii vacuoles mediates host defense. Life Sci Alliance. 2020;3(1):e201900549.

66. Yamamoto M, et al. A cluster of interferon- $\gamma$ inducible p 65 GTPases plays a critical role in host defense against Toxoplasma gondii. Immunity. 2012;37(2):302-313.

67. Collazo CM, et al. Inactivation of LRG-47 and IRG-47 reveals a family of interferon gamma- 
inducible genes with essential, pathogenspecific roles in resistance to infection. J Exp Med 2001;194(2):181-188.

68. Saeij JP, Frickel EM. Exposing Toxoplasma gondii hiding inside the vacuole: a role for GBPs, autophagy and host cell death. Curr Opin Microbiol. 2017;40:72-80.

69. Fleckenstein MC, Reese ML, Könen-Waisman S, Boothroyd JC, Howard JC, Steinfeldt T. A Toxoplasma gondii pseudokinase inhibits host IRG resistance proteins. PLoS Biol. 2012;10(7):e1001358.

70. Etheridge RD, Alaganan A, Tang K, Lou HJ, Turk BE, Sibley LD. The Toxoplasma pseudokinase ROP5 forms complexes with ROP18 and ROP17 kinases that synergize to control acute virulence in mice. Cell Host Microbe. 2014;15(5):537-550.

71. Lima TS, Lodoen MB. Mechanisms of human innate immune evasion by Toxoplasma gondii. Front Cell Infect Microbiol. 2019;9:103.

72. Tsitsiklis A, Bangs DJ, Robey EA. CD8 ${ }^{+}$T cell responses to Toxoplasma gondii: lessons from a successful parasite. Trends Parasitol. 2019;35(11):887-898.

73. Yap G, Pesin M, Sher A. Cutting edge: IL-12 is required for the maintenance of IFN-gamma production in $\mathrm{T}$ cells mediating chronic resistance to the intracellular pathogen, Toxoplasma gondii. JImmunol. 2000;165(2):628-631.

74. Suzuki Y, Orellana MA, Schreiber RD, Remington JS. Interferon-gamma: the major mediator of resistance against Toxoplasma gondii. Science. 1988;240(4851):516-518.

75. Deckert-Schlüter M, et al. Interferon-gamma receptor-deficiency renders mice highly susceptible to toxoplasmosis by decreased macrophage activation. Lab Invest. 1996;75(6):827-841.

76. Schlüter D, et al. Both lymphotoxin-alpha and $\mathrm{TNF}$ are crucial for control of Toxoplasma gondii in the central nervous system. JImmunol. 2003;170(12):6172-6182.

77. Bustamante J, Boisson-Dupuis S, Abel L, Casanova JL. Mendelian susceptibility to mycobacterial disease: genetic, immunological, and clinical features of inborn errors of IFN- $\gamma$ immunity. Semin Immunol. 2014;26(6):454-470.

78. Janssen R, et al. Divergent role for TNF-alpha in IFN-gamma-induced killing of Toxoplasma gondii and Salmonella typhimurium contributes to selective susceptibility of patients with partial IFN-gamma receptor 1 deficiency. J Immunol. 2002;169(7):3900-3907.

79. Jebbari H, Roberts CW, Ferguson DJ, Bluethmann $\mathrm{H}$, Alexander J. A protective role for IL-6 during early infection with Toxoplasma gondii. Parasite Immunol. 1998;20(5):231-239.

80. Wilson EH, Wille-Reece U, Dzierszinski F, Hunter CA. A critical role for IL-10 in limiting inflammation during toxoplasmic encephalitis. J Neuroimmunol. 2005;165(1-2):63-74.

81. Neyer LE, Grunig G, Fort M, Remington JS, Rennick D, Hunter CA. Role of interleukin-10 in regulation of $\mathrm{T}$-cell-dependent and $\mathrm{T}$-cell-independent mechanisms of resistance to Toxoplasma gondii. Infect Immun. 1997;65(5):1675-1682.

82. Gazzinelli RT, et al. In the absence of endogenous IL-10, mice acutely infected with Toxoplasma gondii succumb to a lethal immune response dependent on CD4+ T cells and accompanied by overproduction of IL-12, IFN-gamma and TNF-alpha. J Immunol. 1996;157(2):798-805.

83. Jankovic D, et al. Conventional T-bet(+)Foxp3(-) Th1 cells are the major source of host-protective regulatory IL-10 during intracellular protozoan infection. JExp Med. 2007;204(2):273-283.

84. Hall AO, et al. The cytokines interleukin 27 and interferon- $\gamma$ promote distinct Treg cell populations required to limit infection-induced pathology. Immunity. 2012;37(3):511-523.

85. Oldenhove G, et al. Decrease of Foxp3+ Treg cell number and acquisition of effector cell phenotype during lethal infection. Immunity. 2009;31(5):772-786.

86. Rosowski EE, et al. Strain-specific activation of the NF-kappaB pathway by GRA15, a novel Toxoplasma gondii dense granule protein. JExp Med. 2011;208(1):195-212.

87. Braun L, et al. A Toxoplasma dense granule protein, GRA24, modulates the early immune response to infection by promoting a direct and sustained host 338 MAPK activation. J Exp Med. 2013;210(10):2071-2086.

88. Butcher BA, et al. Toxoplasma gondii rhoptry kinase ROP16 activates STAT3 and STAT6 resulting in cytokine inhibition and arginase-1-dependent growth control. PLoS Pathog. 2011;7(9):e1002236.

89. Ong YC, Reese ML, Boothroyd JC. Toxoplasma rhoptry protein 16 (ROP16) subverts host function by direct tyrosine phosphorylation of STAT6. J Biol Chem. 2010;285(37):28731-28740.

90. Olias P, Etheridge RD, Zhang Y, Holtzman MJ, Sibley LD. Toxoplasma effector recruits the Mi-2/NuRD complex to repress STAT1 transcription and block IFN- $\gamma$-dependent gene expression. Cell Host Microbe. 2016;20(1):72-82.

91. Gay G, et al. Toxoplasma gondii TgIST co-opts host chromatin repressors dampening STAT1dependent gene regulation and IFN- $\gamma$-mediated host defenses. J Exp Med. 2016;213(9):1779-1798.

92. Braun L, et al. The Toxoplasma effector TEEGR promotes parasite persistence by modulating $\mathrm{NF}-\kappa \mathrm{B}$ signalling via EZH2. Nat Microbiol. 2019;4(7):1208-1220.

93. Konradt C, et al. Endothelial cells are a replicative niche for entry of Toxoplasma gondii to the central nervous system. Nat Microbiol. 2016;1:16001.

94. Estato V, et al. The neurotropic parasite Toxoplasma gondii induces sustained neuroinflammation with microvascular dysfunction in infected mice. $A m$ J Pathol.2018;188(11):2674-2687.

95. Schneider CA, et al. Imaging the dynamic recruitment of monocytes to the blood-brain barrier and specific brain regions during Toxoplasma gondii infection. Proc Natl Acad Sci U S A. 2019;116(49):24796-24807.

96. Bierly AL, Shufesky WJ, Sukhumavasi W, Morelli AE, Denkers EY. Dendritic cells expressing plasmacytoid marker PDCA-1 are Trojan horses during Toxoplasma gondii infection. JImmunol. 2008;181(12):8485-8491.

97. Courret N, Darche S, Sonigo P, Milon G, Buzoni-Gâtel D, Tardieux I. CD11c-and CD11b-expressing mouse leukocytes transport single Toxoplasma gondii tachyzoites to the brain. Blood. 2006;107(1):309-316.
98. Pusch L, Romeike B, Deckert M, Mawrin C. Persistent toxoplasma bradyzoite cysts in the brain: incidental finding in an immunocompetent patient without evidence of a toxoplasmosis. Clin Neuropathol. 2009;28(3):210-212.

99. Mendez OA, Koshy AA. Toxoplasma gondii: entry, association, and physiological influence on the central nervous system. PLoS Pathog. 2017;13(7):e1006351.

100.Gazzinelli R, Xu Y, Hieny S, Cheever A, Sher A. Simultaneous depletion of CD4+ and CD8+ T lymphocytes is required to reactivate chronic infection with Toxoplasma gondii. JImmunol. 1992;149(1):175-180.

101.Fischer HG, Nitzgen B, Reichmann G, Gross U, Hadding U. Host cells of Toxoplasma gondii encystation in infected primary culture from mouse brain. Parasitol Res. 1997;83(7):637-641.

102. Cabral CM, et al. Neurons are the primary target cell for the brain-tropic intracellular parasite Toxoplasma gondii. PLoS Pathog. 2016;12(2):e1005447.

103. Melzer TC, Cranston HJ, Weiss LM, Halonen SK. Host cell preference of Toxoplasma gondii cysts in murine brain: a confocal study. J Neuroparasitology. 2010;1:N100505.

104. Hidano S, et al. STAT1 signaling in astrocytes is essential for control of infection in the central nervous system. mBio. 2016;7(6):e01881-16.

105. Melzer T, Duffy A, Weiss LM, Halonen SK. The gamma interferon (IFN-gamma)-inducible GTP-binding protein IGTP is necessary for toxoplasma vacuolar disruption and induces parasite egression in IFN-gamma-stimulated astrocytes. Infect Immun. 2008;76(11):4883-4894.

106. Halonen SK, Weiss LM. Investigation into the mechanism of gamma interferon-mediated inhibition of Toxoplasma gondii in murine astrocytes. Infect Immun. 2000;68(6):3426-3430.

107. Martens S, et al. Disruption of Toxoplasma gondii parasitophorous vacuoles by the mouse $\mathrm{p} 47$ resistance GTPases. PLoS Pathog. 2005;1(3):e24.

108. Peterson PK, Gekker G, Hu S, Chao CC. Human astrocytes inhibit intracellular multiplication of Toxoplasma gondii by a nitric oxide-mediated mechanism. JInfect Dis. 1995;171(2):516-518.

109. Däubener W, et al. Anti-parasitic effector mechanisms in human brain tumor cells: role of interferon-gamma and tumor necrosis factor-alpha. Eur J Immunol. 1996;26(2):487-492.

110. Bando H, et al. Toxoplasma effector GRA15dependent suppression of IFN- $\gamma$-induced antiparasitic response in human neurons. Front Cell Infect Microbiol. 2019;9:140.

111. Chao CC, Hu S, Gekker G, Novick WJ, Remington JS, Peterson PK. Effects of cytokines on multiplication of Toxoplasma gondii in microglial cells. JImmunol. 1993;150(8 pt 1):3404-3410.

112. Chao CC, Gekker G, Hu S, Peterson PK. Human microglial cell defense against Toxoplasma gondii. The role of cytokines. JImmunol. 1994;152(3):1246-1252.

113. Freund YR, Zaveri NT, Javitz HS. In vitro investigation of host resistance to Toxoplasma gondii infection in microglia of BALB/c and CBA/Ca mice. Infect Immun. 2001;69(2):765-772.

114. Sa Q, et al. Cutting Edge: IFN- $\gamma$ produced by brain-resident cells is crucial to control cerebral 
infection with Toxoplasma gondii. JImmunol. 2015;195(3):796-800.

115. Wen X, Kudo T, Payne L, Wang X, Rodgers L, Suzuki Y. Predominant interferon- $\gamma$-mediated expression of CXCL9, CXCL10, and CCL5 proteins in the brain during chronic infection with Toxoplasma gondii in BALB/c mice resistant to development of toxoplasmic encephalitis. J Interferon Cytokine Res. 2010;30(9):653-660.

116. Ochiai E, et al. CXCL9 is important for recruiting immune $T$ cells into the brain and inducing an accumulation of the $\mathrm{T}$ cells to the areas of tachyzoite proliferation to prevent reactivation of chronic cerebral infection with Toxoplasma gondii. Am J Pathol. 2015;185(2):314-324.

117. Salvioni A, et al. Robust control of a brainpersisting parasite through MHC I presentation by infected neurons. Cell Rep. 2019;27(11):3254-3268.e8.

118. Denkers EY, et al. Perforin-mediated cytolysis plays a limited role in host resistance to Toxoplasma gondii. JImmunol. 1997;159(4):1903-1908.

119. Suzuki Y, et al. Removal of Toxoplasma gondii cysts from the brain by perforinmediated activity of CD8+ T cells. Am J Pathol. 2010;176(4):1607-1613.

120. Tiwari A, Hannah R, Lutshumba J, Ochiai E, Weiss LM, Suzuki Y. Penetration of $\mathrm{CD}^{+}$cytotoxic $\mathrm{T}$ cells into large target, tissue cysts of Toxoplasma gondii, leads to its elimination. Am J Pathol. 2019;189(8):1594-1607.

121. Persson EK, et al. Death receptor ligation or exposure to perforin trigger rapid egress of the intracellular parasite Toxoplasma gondii. J Immunol. 2007;179(12):8357-8365.

122. Sidik SM, et al. A genome-wide CRISPR screen in Toxoplasma identifies essential apicomplexan genes. Cell. 2016;166(6):1423-1435.e12.

123. Shen B, Brown KM, Lee TD, Sibley LD. Efficient gene disruption in diverse strains of Toxoplasma gondii using CRISPR/CAS9. mBio. 2014;5(3):e01114-e01114.

124. Soête M, Camus D, Dubremetz JF. Experimental induction of bradyzoite-specific antigen expression and cyst formation by the RH strain of Toxoplasma gondii in vitro. Exp Parasitol. 1994;78(4):361-370.

125. Fox BA, Gigley JP, Bzik DJ. Toxoplasma gondii lacks the enzymes required for de novo arginine biosynthesis and arginine starvation triggers cyst formation. Int J Parasitol. 2004;34(3):323-331.

126. Donald RG, et al. Toxoplasma gondii cyclic GMP-dependent kinase: chemotherapeutic targeting of an essential parasite protein kinase. Eukaryotic Cell. 2002;1(3):317-328.

127. Bohne W, Heesemann J, Gross U. Induction of bradyzoite-specific Toxoplasma gondii antigens in gamma interferon-treated mouse macrophages. Infect Immun. 1993;61(3):1141-1145.

128.Swierzy IJ, et al. Divergent co-transcriptomes of different host cells infected with Toxoplasma gondii reveal cell type-specific host-parasite interactions. Sci Rep. 2017;7(1):7229.

129. Swierzy IJ, Lüder CG. Withdrawal of skeletal muscle cells from cell cycle progression triggers differentiation of Toxoplasma gondii towards the bradyzoite stage. Cell Microbiol.2015;17(1):2-17.

130. Saksouk N, et al. Histone-modifying complexes regulate gene expression pertinent to the differentiation of the protozoan parasite Toxoplasma gondii. Mol Cell Biol. 2005;25(23):10301-10314.

131. Naguleswaran A, Elias EV, McClintick J, Edenberg HJ, Sullivan WJ. Toxoplasma gondii lysine acetyltransferase GCN5-A functions in the cellular response to alkaline stress and expression of cyst genes. PLoS Pathog. 2010;6(12):e1001232.

132. Bougdour A, et al. Drug inhibition of HDAC3 and epigenetic control of differentiation in Apicomplexa parasites. J Exp Med. 2009;206(4):953-966.

133. Sullivan WJ, Narasimhan J, Bhatti MM, Wek RC. Parasite-specific eIF2 (eukaryotic initiation factor-2) kinase required for stress-induced translation control. Biochem $J$. 2004;380 (pt 2):523-531.

134. Konrad C, Queener SF, Wek RC, Sullivan WJ. Inhibitors of eIF2 $\alpha$ dephosphorylation slow replication and stabilize latency in Toxoplasma gondii. Antimicrob Agents Chemother. 2013;57(4):1815-1822.

135. Walker R, et al. The Toxoplasma nuclear factor TgAP2XI-4 controls bradyzoite gene expression and cyst formation. Mol Microbiol. 2013;87(3):641-655.

136. Hong DP, Radke JB, White MW. Opposing transcriptional mechanisms regulate Toxoplasma development. mSphere. 2017;2(1):e00347-16

137. Radke JB, et al. Transcriptional repression by ApiAP2 factors is central to chronic toxoplasmosis. PLoS Pathog. 2018;14(5):e1007035.

138. Waldman BS, Schwarz D, Wadsworth MH, Saeij JP, Shalek AK, Lourido S. Identification of a master regulator of differentiation in Toxoplasma. Cell. 2020;180(2):359-372.e16.

139. Skariah S, McIntyre MK, Mordue DG. Toxoplasma gondii: determinants of tachyzoite to bradyzoite conversion. Parasitol Res. 2010;107(2):253-260.

140. Buchholz KR, Bowyer PW, Boothroyd JC. Bradyzoite pseudokinase 1 is crucial for efficient oral infectivity of the Toxoplasma gondii tissue cyst. Eukaryotic Cell. 2013;12(3):399-410.

141. Zhang YW, Halonen SK, Ma YF, Wittner M, Weiss LM. Initial characterization of CST1, a Toxoplasma gondii cyst wall glycoprotein. Infect Immun. 2001;69(1):501-507.

142. Tomita $\mathrm{T}$, et al. The Toxoplasma gondii cyst wall protein CST1 is critical for cyst wall integrity and promotes bradyzoite persistence. PLoS Pathog. 2013;9(12):e1003823.

143. Caffaro CE, Koshy AA, Liu L, Zeiner GM, Hirschberg CB, Boothroyd JC. A nucleotide sugar transporter involved in glycosylation of the Toxoplasma tissue cyst wall is required for efficient persistence of bradyzoites. PLoS Pathog. 2013;9(5):e1003331.

144. Nance JP, et al. Chitinase dependent control of protozoan cyst burden in the brain. PLoS Pathog. 2012;8(11):e1002990.

145. Wang AW, et al. Genome-wide association study in two populations to determine genetic variants associated with Toxoplasma gondii infection and relationship to schizophrenia risk. Prog Neuropsychopharmacol Biol Psychiatry. 2019;92:133-147.

146. Fekkar A, et al. Direct genotyping of Toxoplasma gondii in ocular fluid samples from 20 patients with ocular toxoplasmosis: predominance of type II in France. J Clin Microbiol. 2011;49(4):1513-1517.

147. Herrmann DC, et al. Genotyping of samples from German patients with ocular, cerebral and systemic toxoplasmosis reveals a predominance of Toxoplasma gondii type II. Int J Med Microbiol. 2014;304(7):911-916.

148.Holland GN. Ocular toxoplasmosis: a global reassessment. Part I: epidemiology and course of disease. Am JOphthalmol. 2003;136(6):973-988.

149. Bosch-Driessen LE, Berendschot TT, Ongkosuwito JV, Rothova A. Ocular toxoplasmosis: clinical features and prognosis of 154 patients. Ophthalmology. 2002;109(5):869-878.

150. Vishnevskia-Dai V, et al. Chorio-retinal toxoplasmosis: treatment outcomes, lesion evolution and long-term follow-up in a single tertiary center. Int Ophthalmol.2020;40(4):811-821.

151. Smith JR, Franc DT, Carter NS, Zamora D, Planck SR, Rosenbaum JT. Susceptibility of retinal vascular endothelium to infection with Toxoplasma gondii tachyzoites. Invest Ophthalmol Vis Sci. 2004;45(4):1157-1161.

152. Tedesco RC, Smith RL, Corte-Real S, Calabrese KS. Ocular toxoplasmosis: the role of retinal pigment epithelium migration in infection. Parasitol Res. 2004;92(6):467-472.

153. Charles E, et al. CD4 T-cell suppression by cells from Toxoplasma gondii-infected retinas is mediated by surface protein PD-L1. Infect Immun. 2010;78(8):3484-3492.

154.Calabrese KS, Tedesco RC, Zaverucha do Valle T, Barbosa HS. Serum and aqueous humour cytokine response and histopathological alterations during ocular Toxoplasma gondii infection in C57BL/6 mice. Micron. 2008;39(8):1335-1341.

155. Rochet É, et al. Interleukin-6-driven inflammatory response induces retinal pathology in a model of ocular toxoplasmosis reactivation. Infect Immun. 2015;83(5):2109-2117.

156.Iqbal J, Al-Awadhi MA, Raghupathy RG. TGF- $\beta 1$ levels and intraocular tissue alterations in mice infected with a virulent type I RH Toxoplasma gondii strain. Exp Parasitol. 2016;162:57-63.

157. de-la-Torre A, et al. Severe South American ocular toxoplasmosis is associated with decreased Ifn- $\gamma /$ Il-17a and increased Il-6/Il-13 intraocular levels. PLoS Negl Trop Dis. 2013;7(11):e2541.

158. Vyas A, Kim SK, Giacomini N, Boothroyd JC, Sapolsky RM. Behavioral changes induced by Toxoplasma infection of rodents are highly specific to aversion of cat odors. Proc Natl Acad Sci US A. 2007;104(15):6442-6447.

159. Berdoy M, Webster JP, Macdonald DW. Fatal attraction in rats infected with Toxoplasma gondii. Proc Biol Sci. 2000;267(1452):1591-1594.

160.Wang ZT, Harmon S, O'Malley KL, Sibley LD. Reassessment of the role of aromatic amino acid hydroxylases and the effect of infection by Toxoplasma gondii on host dopamine. Infect Immun. 2015;83(3):1039-1047.

161. McFarland R, et al. AAH2 gene is not required for dopamine-dependent neurochemical and behavioral abnormalities produced by Toxoplasma infection in mouse. Behav Brain Res. 2018;347:193-200.

162.Wang ZT, Verma SK, Dubey JP, Sibley LD. 
The aromatic amino acid hydroxylase genes AAH1 and AAH2 in Toxoplasma gondii contribute to transmission in the cat. PLoS Pathog. 2017;13(3):e1006272.

163. Ingram WM, Goodrich LM, Robey EA, Eisen MB. Mice infected with low-virulence strains of Toxoplasma gondii lose their innate aversion to cat urine, even after extensive parasite clearance. PLoS One. 2013;8(9):e75246.

164. Ferrero DM, et al. Detection and avoidance of a carnivore odor by prey. Proc Natl Acad Sci U S A. 2011;108(27):11235-11240.

165. Arsenijevic D, Bilbao FD, Giannakopoulos P, Girardier L, Samec S, Richard D. A role for interferon-gamma in the hypermetabolic response to murine toxoplasmosis. Eur Cytokine Netw. 2001;12(3):518-527.

166.Zhou CX, Zhou DH, Elsheikha HM, Liu GX, Suo $\mathrm{X}$, Zhu XQ. Global metabolomic profiling of mice brains following experimental infection with the cyst-forming Toxoplasma gondii. PLoS One. 2015;10(10):e0139635.

167. Zhou CX, Zhou DH, Elsheikha HM, Zhao Y, Suo $\mathrm{X}$, Zhu XQ. Metabolomic profiling of mice serum during toxoplasmosis progression using liquid chromatography-mass spectrometry. Sci Rep. 2016;6:19557.

168. Melchor SJ, Ewald SE. Disease tolerance in Toxoplasma infection. Front Cell Infect Microbiol. 2019;9:185.
169. Kugler DG, et al. Systemic toxoplasma infection triggers a long-term defect in the generation and function of naive T lymphocytes. J Exp Med. 2016;213(13):3041-3056.

170.Arsenijevic D, et al. Metabolic-cytokine responses to a second immunological challenge with LPS in mice with T. gondii infection. Am J Physiol. 1998;274(3):E439-E445.

171. Melchor SJ, et al. IL-1R regulates disease tolerance and cachexia in toxoplasma gondii infection. J Immunol. 2020;204(12):3329-3338

172. Jin RM, Blair SJ, Warunek J, Heffner RR, Blader IJ, Wohlfert EA. Regulatory T cells promote myositis and muscle damage in Toxoplasma gondii infection. JImmunol. 2017;198(1):352-362. 